\title{
La construcción de un centro cultural desde la periferia: Juan Filloy y el Museo de Bellas Artes de Río Cuarto
}

The construction of a cultural center from the periphery: Juan Filloy and the Museum of Fine Arts of Río Cuarto

\section{Martina Guevara}

\section{(2) OpenEdition}

\section{Journals}

Electronic version

URL: http://journals.openedition.org/corpusarchivos/2107

DOI: 10.4000/corpusarchivos. 2107

ISSN: 1853-8037

Publisher

Diego Escolar

\section{Electronic reference}

Martina Guevara, "La construcción de un centro cultural desde la periferia: Juan Filloy y el Museo de Bellas Artes de Río Cuarto », Corpus [En línea], Vol. 8, No 1 | 2018, Publicado el 02 julio 2018, consultado el 19 abril 2019. URL : http://journals.openedition.org/corpusarchivos/2107 ; DOI 10.4000/corpusarchivos.2107

This text was automatically generated on 19 April 2019.

Licencia Creative Commons: Atribución-NoComercial 2.5 Argentina (CC BY-NC 2.5 AR) 


\title{
La construcción de un centro cultural desde la periferia: Juan Filloy y el Museo de Bellas Artes de Río Cuarto
}

\author{
The construction of a cultural center from the periphery: Juan Filloy and the \\ Museum of Fine Arts of Río Cuarto
}

Martina Guevara

Introducción

Este artículo realiza un análisis crítico de los procesos de gestación y desarrollo inicial del Museo Municipal de Bellas Artes de Río Cuarto (Córdoba) entre 1933-1943. El papel de su primer director, el escritor literario Juan Filloy, conforma el foco central de examen y permite un acercamiento exploratorio para el análisis interdisciplinario de áreas de estudio que tienden a abordarse de manera fragmentaria. La particular combinación del rol de escritor de Filloy con su función de director del Museo constituye un campo fértil para abordar las relaciones y tensiones existentes e inexploradas dentro del área de los estudios culturales entre la historia de la literatura y la historia de la conformación del patrimonio, en particular aquella dedicada a la cultura material y a los procesos de conformación de museos de arte. Entre ellas podrían mencionarse la construcción de la figura de intelectual/animador cultural en ámbito de provincia; las relaciones interpersonales sobre la que se sustenta esta construcción; la actuación en la esfera pública y privada; las conexiones con la administración estatal a través de un museo organizado con donaciones privadas; la organización de colecciones; y las relaciones entre la obra literaria de Filloy y el museo que dirige. La investigación se sustenta principalmente en el examen de fuentes primarias: el libro de Actas del Museo Municipal de Bellas Artes de Río Cuarto, ${ }^{1}$ que se conserva en su sede actual y cuya riqueza, como la de tantas instituciones museísticas aún sin examinar, merece el interés de futuras investigaciones, y una serie de cartas dirigidas a Filloy, que pudimos analizar dentro de la cuantiosa correspondencia al escritor que se encuentra en el Archivo Histórico Municipal 
de Río Cuarto. ${ }^{2}$ Además cumple un rol relevante en este trabajo la correspondencia de Ricardo Montes i Bradley a Filloy recopilada en El Amigo de Filloy (2014) y las declaraciones o discursos del propio Filloy extraídas de la biografía sobre el escritor cordobés recientemente escrita por Ariel Magnus (2017).

El Museo Municipal de Bellas Artes de Río Cuarto, gestado en 1933, no solo fue el primer museo exclusivamente dedicado al arte de su ciudad sino, en sentido estricto, de la provincia de Córdoba. El Museo Politécnico de Córdoba, fundado en 1887 e inaugurado recién en 1889, mantuvo una voluntad generalista -anacrónica con respecto a las tendencias especializantes que en ese momento hacían mella en Buenos Aires- (Agüero 2009) hasta, por lo menos, 1911. Ese año se instituye por decreto la separación del área dedicada a las Ciencias Naturales y se crea una galería de Pintura y Escultura, gestionada conjuntamente por los directores del Museo y la Academia Provincial. En 1922, la sección artística queda bajo la órbita exclusiva de la Academia Provincial. El "Salón de Bellas Artes", tal como era mencionado en el presupuesto provincial, recién tendrá un director independiente de la Academia - Antonio Pedone- en octubre de 1930, fruto de la intervención golpista que crea ese cargo. Aun así, la denominación de Museo Provincial de Bellas Artes bajo el nombre de "Emilio Caraffa" no llegará hasta 1950.

La distinción señalada entre 'salón' y 'museo' trasciende la minucia semántica y se inscribe en la serie de procesos que experimentan los espacios dedicados al arte entre fines del siglo XIX y principios del XX. Si bien los salones mantienen una relación de cercanía con la idea de exhibición en tanto "institución” (Baldasarre 2006, p. 40), conservan también cierta proximidad con las empresas comerciales dedicadas al arte e intensificadas desde finales del siglo XIX. ${ }^{3}$ Aunque el rédito económico no es lo que motiva la conformación del Salón de Bellas Artes en Córdoba, Antonio Pedone solicita en 1942 al vicegobernador de la provincia, Arturo U. Illia, el cambio de nomenclatura. Entre las cinco razones que enumera en su carta, elige comenzar por la siguiente:

El título con que figura en el Presupuesto de "Salón de Bellas Artes", es un error, ya que, "Salón", presupone algo transitorio y no permanente. "Salón de Bellas Artes" se le llama, en Europa y en nuestro país, a las exposiciones de tiempo limitado. Este error de nominación es lamentable por la confusión que trae, tanto en las cuestiones de orden administrativo como así también en las gestiones ante los demás Museos del país. Y también por perder la jerarquía que todo Museo de Bellas Artes debe tener. ${ }^{4}$ La idea del museo como reservorio permanente de valores con significancia histórica para una nación tiene su origen en las transformaciones que en la relación con el pasado se producen en la Francia postrevolucionaria y que se plasman de manera temprana en la conformación del Museo del Louvre y del Museo de los Monumentos Franceses (Revel 2014). En 1830 se crea en Francia el cargo de inspector de monumentos y en 1837 se inaugura, en el mismo país, la Comisión de Monumentos Históricos. No obstante, la noción de patrimonio tuvo una espectacular extensión durante el siglo XX en el plano internacional, sobre todo a partir del período de entreguerras y el primer Congreso Internacional de Arquitectos y Especialistas de Monumentos Históricos, en 1931; el término fue adoptado progresivamente en los años 1960-1970 y en especial después de la votación en 1972 en la Unesco a favor de una convención para la protección del patrimonio mundial. Finalmente, en los años 80 , la oleada patrimonial en consonancia con los postulados teóricos de Pierre Nora fue cobrando cada vez más importancia hasta aproximarse al límite que sería el 'todo-es-patrimonio' (Heinich 2014). Desplazada hacia finales del siglo XIX, la idea de patrimonio pensado como un derecho colectivo presenta sus propias particularidades en la Argentina. Entre ellas, la proximidad 
en la fechas de fundación del Museo Histórico Nacional (1889) y del Museo Nacional de Bellas Artes (1895). El análisis crítico que propone Malosetti Costa (2010; 2016) invita a reflexionar sobre el deslindamiento con que la bibliografía especializada abordó los dos tipos de museos. La relación comparativa que establece entre los procesos de gestación del Museo Histórico Nacional y del Museo Nacional de Bellas Artes, sobre todo a partir de los artefactos visuales que conformaron ambas colecciones, permite dar cuenta de que la finalidad de este último no distaba en demasía del dedicado a la historia; las dos instituciones se inscriben y se involucran en el proceso de consolidación del Estado y la construcción del sentimiento nacional colectivo. De este modo, si bien el Museo de Historia Nacional buscó afianzar el patriotismo público y el Museo Nacional de Bellas Artes persiguió el objetivo de insertar a la nación argentina en una red cosmopolita más amplia, ambos organizaron dos rituales de civilización complementarios entre sí y estratégicos para los objetivos 'civilizatorios' y pedagógicos de la elite gobernante. De manera coincidente, la tarea de alcanzar y cultivar a un público masivo era parte de la intencionalidad manifiesta de Antonio Pedone. En una entrevista publicada en la Voz del Interior el 29 de noviembre de 1930 (a unos días de la asunción de Pedone a su nuevo cargo) se realiza la siguiente aseveración:

Decíamos que Pedone no había ido al cargo a sentar plaza de burócrata ni a hacerse en él personalidad, que la tiene y sólida desde mucho. Él ha convertido su nombramiento para la dirección del Museo, ${ }^{5}$ en una oportunidad seria y sistemática de trabajo. Un plan de divulgación artística, es por ejemplo, uno de los puntos fundamentales de su acción. Sin embargo, pionera como fue en el marco de la capital cordobesa, la empresa no tuvo un acompañamiento financiero a nivel estatal. En la misma nota, Antonio Pedone manifiesta su preocupación por dicha situación y se pregunta “ ¿Cómo puede dicha institución cumplir su finalidad de acumular obras de arte, si empieza por no contar con qué adquirirlas?" ("Conversando con Antonio Pedone. Director del Museo Provincial de Bellas Artes", 1930).

La falta de respaldo financiero estatal que sufrió el Salón de Bellas Artes de la provincia de Córdoba dista de ser un hecho aislado. Gestado, como se vio, en un contexto en que las artes plásticas fueron debatidas en términos de un proyecto de nación y consideradas síntoma del grado de civilización alcanzado por un pueblo (Malosetti Costa 2001), ${ }^{6}$ el Museo Nacional de Bellas Artes tampoco contó en sus inicios con una partida presupuestaria para la adquisición de obra.

La institución artística central -en términos de hegemonía - fue creada dentro del espectro temporal que la crítica especializada bautizó "movimiento internacional de fundación de museos" (Farro 2008, p.3), pero en el que el Estado argentino "no estaba sólidamente constituido sino que era más bien una entidad compleja que incluáa ámbitos ya consolidados y otros apenas en procesos de construcción y/o proyección" (Carman 2013, p. 20) produciendo que los museos se desarrollasen principalmente por iniciativa de voluntades surgidas del ámbito privado. ${ }^{7}$ En efecto, la identificación acrítica entre museos, memoria y representación de la nación fue discutida de manera pionera por Irina Podgorny en relación específica con los museos de Historia Natural como loci privilegiados de la infraestructura de las ciencias y del saber en el siglo XIX. Lejos de constituirse como instrumentos del poder estatal para consolidar una representación de la nación afín a sus intereses, en el caso argentino, el Estado y la nación no llevaron adelante la creación de museos sino que necesitaron de individuos flexibles a los rumbos de la política, quienes supieron entretejer su prestigio personal y su red de relaciones con los supuestos intereses de la nación (Podgorny 2005). Tal es el caso del Museo Público de 
Buenos Aires o del Museo de La Plata. A su vez las colecciones y directores se insertaban en una red internacional de intercambio de datos, de publicaciones, de saberes y prácticas ligadas a la promoción de un tipo arquitectónico, de formas de exhibición y organización de las disciplinas científicas (Podgorny y Lopes 2013).

Por el contrario, los más de 30 años que transcurren hasta la inauguración del "Salón de Bellas Artes" de la capital cordobesa y, subsiguientemente, del Museo Municipal de Bellas Artes de Río Cuarto inscriben la formación de estas instituciones en un contexto que, prima facie, vuelve más notoria la falta de acompañamiento estatal.

Se ha caracterizado a los años 30 por ser el período donde se sientan las bases para delinear las fronteras de la historia nacional y consagrar ciertos objetos y colecciones de los museos no solo como patrimonio histórico sino más aún como patrimonio moral de la nación (Blasco 2012b). Esta construcción historiográfica, que presenta como hechos icónicos la creación de la Comisión Nacional de Museos, Monumentos y Lugares Históricos (CNMMyLH) y la sanción de la Ley Nacional $\mathrm{N}^{\circ} 12.665$, se encuadra dentro de los cambios que operaron en esos años para que la historia se volviese la base de legitimización social de un Estado que había perdido su sustento institucional. De este modo, considerada la memoria histórica un asunto de Estado, "las gestiones gubernativas que se sucedieron en adelante reforzaron las tendencias (...) a la instalación de lugares de memoria" (Suárez y Saab 2012, p. 213). Sin embargo, tal como lo demuestra el análisis de casos específicos $^{8}$ el desarrollo de gran parte de los museos durante la década del 30 siguió respondiendo en mayor o menor medida, más que a un objetivo de sustentación ideológica del Estado, a proyectos guiados por fines de rentabilidad turística o intereses privados. En efecto, el rol de promotores privados cuyas ambiciones personales llevaron a la concreción del patrimonio cultural del país, supliendo la carencia del mecenazgo oficial, no parece ser un fenómeno que encuentre sus límites en el decenio iniciado en los 30, ${ }^{9}$ sobre todo a nivel provincial. En este sentido, la formación del Museo Municipal de Bellas Artes de Río Cuarto se inscribe, con sus propias particularidades, dentro de los casos en los que los problemas inherentes a la hora de organizar un museo público con donaciones privadas y escaso financiamiento estatal llevan a estructurar esas instituciones sobre redes de sociabilidad privada. Entre ellas, las que su primer director, Juan Filloy, ${ }^{10}$ trazó junto a Antonio Pedone.

Los inicios

El 5 de julio de 1933, en un selecto acto, don Carlos A. Vismara, intendente municipal de Río Cuarto, se reúne en su despacho junto con el director del Museo Provincial de Bellas Artes, Don Antonio Pedone, y con Juan Filloy, "vecino de esta ciudad", para firmar el acta 
que dará por inaugurado el Museo Municipal de Bellas Artes. Juan Filloy es nombrado director "ad honorem del museo". ${ }^{11}$

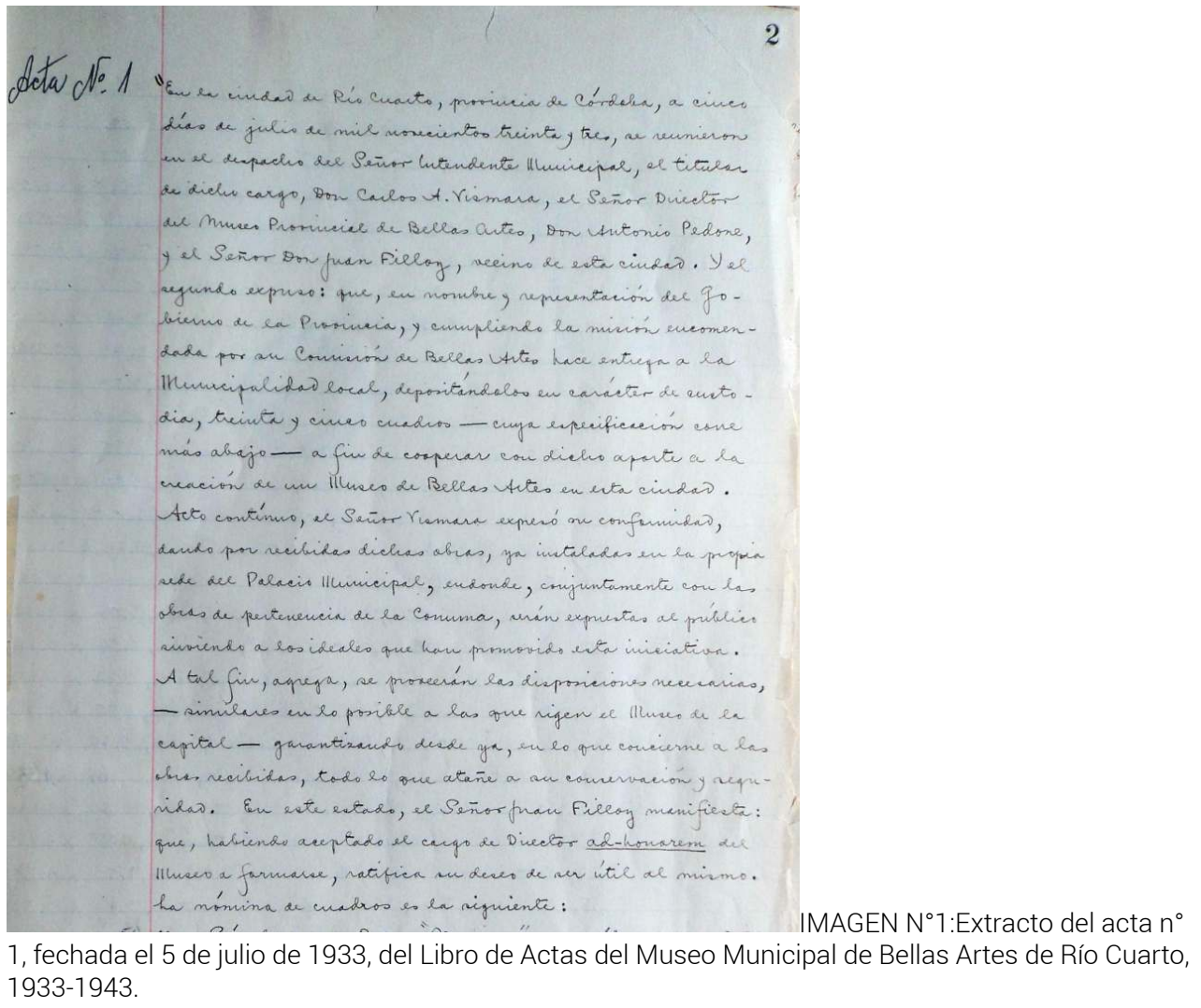

Si nos guiásemos únicamente por el documento, no deja de sorprender el apoyo que este "vecino" obtiene por parte del Estado. A nivel municipal, se brinda una legitimación oficial al incipiente museo otorgándole parte del Palacio Municipal como sede; a su vez, Pedone en "nombre y representación del Gobierno de la Provincia, y cumpliendo la misión encomendada por su Comisión de Bellas Artes"12 entrega a la municipalidad local, en carácter de custodia, treinta y cinco cuadros "a fin de cooperar con dicho aporte a la creación de un Museo de Bellas Artes de esta ciudad". ${ }^{13}$ Entre las firmas de las obras de las que Juan Filloy se compromete a garantizar "todo lo que atañe a su conservación y seguridad" 14 varias cuentan ya para ese entonces con un prestigio alto en el campo artístico, como es el caso de Eugenio Daneri, Luis Cordiviola, Augusto Ballerini, Pablo Molinari, Domingo Ángel Vena y Ulpiano Checa. Su aporte para la colección del Museo Municipal, si bien se diluye dentro de un conjunto de piezas de menor valor, constituye un respaldo que excede lo simbólico, más si se tiene en cuenta que, como habíamos mencionado, el Salón de Bellas Artes no contaba para ese entonces con una partida fija para adquisición de obras.

Sin embargo, la razón por la cual Pedone decide designar esas obras al Museo Municipal parece no trascenderlo. Es difícil atribuir la donación a una decisión política impulsada por el Gobierno Provincial, en ese momento a cargo del gobernador Pedro José Frías. Frías, quien había llegado al poder provincial tras la renuncia por motivos de salud del gobernador electo Emilio Olmos, era miembro del Partido Demócrata y pertenecía a la facción menos proclive - dentro del conservadurismo- a comprometer el lineamiento republicano y democrático defendido por su predecesor. Vismara, por su parte, era un reconocido radical con simpatías por el fascismo italiano. Esto hace cuanto menos 
sospechar que las motivaciones de las generosas donaciones realizadas por el posteriormente denominado Museo Caraffa al incipiente Museo Municipal de Río Cuarto corrieron por vías alternas a las institucionales.

Sin embargo, en la revisión de las fuentes ya mencionadas no pudimos hallar evidencia que corroborase una amistad entre Pedone y Filloy preexistente al de la gestación del Museo Municipal.

Triangular la relación a partir del vínculo que ambos personajes - podemos inferircompartían con Deodoro Roca permite comenzar a esbozar una explicación sobre las motivaciones de la donación y los intereses que en ella se ponían en juego. La figura de Deodoro Roca como un actor central en la renovación de la escena cultural cordobesa ha sido abordada por abundante bibliografía (Portantiero 1978; Kohan 1999; Vásquez 2000; Sanguinetti 2003; Requena 2009) y, en específico, en relación con el Museo Politécnico y sus consecuentes derivaciones, por Agüero (2009). De ahí, que podamos comprender la relevancia del apoyo público que Deodoro Roca le brinda a Pedone cuando, en medio de controversias, asume la dirección del Salón de Bellas Artes de Córdoba (Antonio Pedone, director del Museo, 2014). Por su parte, Pedone, junto al pedido anteriormente citado para que el salón dirigido por él alcanzase la categoría de museo, solicita que la institución sea bautizada "Deodoro Roca". En cuanto al vínculo entre Deodoro Roca y Filloy, si bien no ha sido trabajado de manera exhaustiva por la crítica, es catalogado como de amistad por Ariel Magnus (2017) quien, además, da cuenta a partir de una carta en torno a OpOloop de la admiración que el líder de la Reforma Universitaria del 18 profesaba por el escritor: "mi querido y admirado amigo (...) Tengo necesidad de decir cómo y por qué, desde hace tiempo, le tengo sin hipérbole, por el primer hombre de letras de la Argentina" (2017 p. 39). De hecho, Deodoro Roca "le implora" (Bergel 2012, p. 15) a Filloy que colabore en su revista Flecha fundada en 1935 y que, luego de 17 números, interrumpe su tirada en 1936. Aunque lo antedicho mantiene las razones de la colaboración del Salón de Bellas Artes (a la que, como veremos, se sumarán otros préstamos y donaciones) dentro del plano especulativo, el aval literario con el que contó Filloy por parte de una figura trascendente en el campo intelectual como Deodoro Roca permite comenzar a echar luz sobre el capital social y simbólico con el que contaba Filloy y sus consecuentes derivaciones para la gestación y el sostenimiento del Museo Municipal.

Aparte del compromiso asumido por Filloy en el cuidado de las obras, en el acta inaugural se repite $-\mathrm{y}$ hasta se subraya- el carácter ad honorem del nuevo puesto a ocupar. Su figura se alinea así a la de otros promotores culturales como Enrique Udaondo y Juan B. Castagnino que, desde emprendimientos periféricos, se encargaron de disminuir "las sumas de dinero que debía invertir la administración” (Blasco 2011c, p. 48) y dejar constancia de que no recibiría una retribución económica por su tarea. El dinero ahorrado, claro está, serviría para sumar recursos para el museo.

No obstante, a diferencia de los directores del Museo Histórico y Colonial de la Provincia de Buenos Aires y de Museo de Bellas Artes, Juan Filloy no era ni un hombre de fortuna personal ni miembro de las elites de su provincia. Su profesión, a su vez, no estaba relacionada con la artes. Hijo de inmigrantes (de Francia, por el lado de madre y de España, por la línea paterna) quienes "nunca vivieron bajo techo propio" (Tentoni 2016, p. 6) cursó la carrera de Derecho en la Universidad de Córdoba, de la cual se recibió en 1919. Su arribo a Río Cuarto, doce años antes de la fundación del museo, se debe a un nombramiento, no requerido, de "Asesor Letrado de Menores de la Justicia Provincial" en esa ciudad, más allá de que el mito que se fue forjando priorice para explicarlo una fascinación repentina del escritor por Río Cuarto (Tentoni 2016, p. 37). 
El hecho de que un advenedizo se erigiese como el director del primer Museo de Artes Plásticas de la ciudad encuentra una explicación a partir de las herramientas teóricas propuestas por Eujanian (2013) y especialmente por Martínez (2013). Eujanian sostiene que en las provincias argentinas prevaleció por más tiempo una indiferenciada 'república de la letras' por sobre la especialización académica. En esta misma línea, la figura del 'intelectual' de provincia propuesta por Martínez (2013) se aleja de la concepción clásica de intelectual de la tradición bourdiana (en tanto actores dedicados a la producción de ideas en un campo autónomo del saber con reglas definidas de comportamiento), para encontrar una aproximación más idónea en la figura del productor cultural conceptualizada por Raymond Williams. La incidencia del locus donde operan los intelectuales de provincia propone unos límites menos estables entre las esferas de conocimiento, lo que lleva a quitarle especificidad (y mayor valor de cambio) al capital simbólico acumulado. Entre las cinco características con las que Martínez (2013) define el perfil y el contexto de estos intelectuales, nos interesa destacar, para el caso de Filloy, la siguiente:

Esta inexistencia o limitación de los campos de producción específica son el producto y a la vez generan la inespecificidad del capital simbólico que se acumula y canjea: la publicación de un libro que muy pocas personas localmente han leído o leerán genera sin embargo el halo de intelectualidad que marca más un lugar social que una competencia. Las colecciones de lujo de autores locales que publican instituciones ligadas al poder local, con el mero objeto de ser exhibidas, forman parte de este juego de complacencias (Martínez 2013, p. 175).

En efecto, para julio de 1933, Filloy tenía ya tres obras publicadas en ediciones privadas encargadas a Ferrari Hermanos: Periplo (1930), ¡ Estafen! (1931) y Balumba (1932). Estos 'marcadores' de intelectualidad se suman, entonces, al prestigio del título universitario y a su pertenencia institucional. La Universidad de Córdoba era una marca de un lugar social de pertenencia que generaba espacios de poder, como explica también Martínez (2013), más estables incluso que la del prestigio científico o artístico. En este punto, debemos hacer foco en la distinción realizada por Martínez (2013) entre intelectual de pueblo y de provincia, a la que se debería acompañar de otros abordajes teóricos como el de Agüero y García (2016) que invitan a pensar el interior del país no como un todo homogéneo sino como una multiplicidad de realidades complejas que llevan, incluso, a teorizar sobre un 'interior del interior'. Si bien Río Cuarto se caracterizó, como señala Escudero (2015), por la insistencia de su autonomía respecto de Córdoba capital, no debería descartarse la capacidad de influencia de un intelectual de capital en términos similares a los que Buenos Aires traza con el resto de las provincias. Sobre todo, si se piensa que la Universidad de Río Cuarto fue recién fundada en 1971.

Recapitulando lo antedicho, puede inferirse que, ya en 1933, Filloy contaba con el capital simbólico suficiente como para que se le confiase la dirección del primer museo de bellas artes de esta ciudad del interior provinciano.

El papel de Filloy en Río Cuarto supera, no obstante, el de un actor influyente en el campo cultural de su lugar de residencia. Recién llegado a Río Cuarto, bastante antes de gestar y dirigir el museo, Filloy había logrado participar (ad honorem) en el diario El Pueblo; fundar y dirigir la biblioteca del Club Sportivo Atenas; y estar entre los socios fundadores del primer Club de Golf de la ciudad. En torno al Museo Municipal, también creó la Asociación de Amigos del Arte (formalizada recién en la década del 40), entre cuyos integrantes se encontraba Joaquín Bustamante con quien, ya en los años 50, llevaría adelante la revista Trapalanda. De este modo, el involucramiento de Filloy en la esfera intelectual de Río 
Cuarto trasciende la necesidad de inserción en su nueva ciudad de residencia para pasar a formar parte de la propia construcción de ese campo. Convertido en un animador cultural inespecífico, consideramos que los esfuerzos por promover la cultura y el arte en Río Cuarto se dimensionan si se piensan, en palabras de Martínez (2013), que fueron efectuados: "con la secreta esperanza de producir los interlocutores y el espacio de intercambio del que carecen" (p. 176).

La colección

Los aportes de Pedonde al museo continuaron luego de la fundación. Durante el período que compete a este artículo se pudieron documentar dos intervenciones adicionales. En la primera, datada el 14 de abril de 1934, Pedone dona dos aguafuertes de su autoría:

"Capilla del cementerio viejo, Ávila" y "Ciudadela, Pisa"; 15 en la segunda, efectuada un año después, el 25 abril de $1935^{16}$ se envían trece obras pertenecientes al "Museo Provincial de Bellas Artes" de Córdoba, para su "exhibición permanente" en la institución homónima de Río Cuarto. Dentro de la lista figuran piezas de valor significativo como un óleo de Guillermo Butler y una obra de la misma técnica firmada por José Malanca.

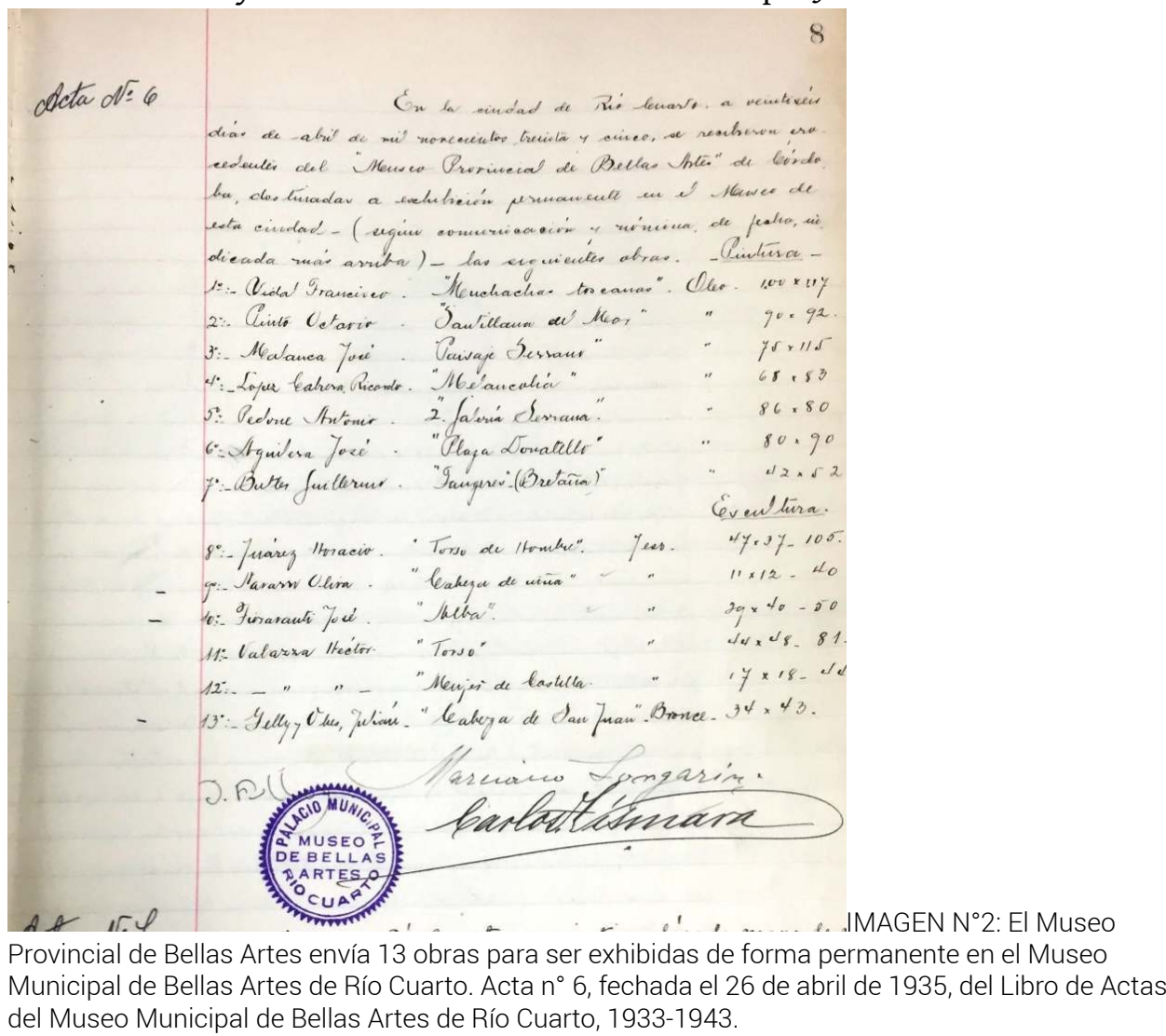

Aunque importantes, las colaboraciones del Salón de Bellas Artes de la capital cordobesa no fueron las únicas que permitieron que, para 1943, el joven Museo Municipal de Bellas Artes contase con un acervo de 262 obras. En consecuencia, motivará este apartado dar cuenta de la procedencia de parte de dichas piezas, así como las estrategias diseñadas por Juan Filloy, en tanto director del museo, para que formasen parte de la colección. Interrogarnos sobre el proceso constitutivo del primer patrimonio artístico de Río Cuarto supone un abordaje crítico que entiende a las colecciones como portadoras de una significancia que trasciende su cualidad artística para visibilizar sus procesos de reproducción, circulación y consumo. En este punto, nuestra investigación es tributaria 
de la noción de ‘semiósforo’ de Krzysztof Pomian recuperada por Farro (2008) para su análisis crítico del Museo de La Plata:

Las colecciones pueden ser entendidas como instituciones coextensivas al hombre en el tiempo y en el espacio, producto de un comportamiento sui generis que consiste precisamente en formar colecciones, cuyo principal papel, en el que se insertan todos los demás, es el de vínculo entre lo invisible y lo visible: a partir de estos objetos tangibles se puede hacer visible y estable lo que de otra manera sería invisible y evanescente (Farro 2008, p. 19).

De este modo, el concepto ampliado de 'colección' nos permite analizar, a través de la historia que se inscribe en los objetos que la conforman, ${ }^{17}$ las relaciones que a partir del Museo Municipal se tejieron entre donantes del ámbito privado, contribuciones de otros museos y funcionarios estatales.

Si un afluente fundamental de obras lo ocupó la capital cordobesa, otros centros relevantes de donaciones fueron la ciudad de La Plata ${ }^{18} \mathrm{y}$, muy especialmente, Rosario. El 21 de junio de 1939 ingresaron al museo dos obras "donadas por sus respectivos autores" de los artistas rosarinos Leónidas Gambartes y Lino Spilimbergo. La remisión de esas piezas fue facilitada por Montes i Bradley, crítico de arte y figura destacada del campo cultural de Rosario. ${ }^{19}$ A su vez, con fecha del 14 octubre de $1941,{ }^{20}$ ingresa al museo, procedente de la "Comisión Municipal de Cultura" de Rosario, un óleo de Manuel Musto que había sido adjudicada conforme a disposiciones testamentarias del artista. ${ }^{21}$ Por otra parte, si bien en 1937 es el Museo Municipal el que adquiere dieciocho obras (en su mayor parte xilografías de artistas santafesinos), esta entrada se efectúa por recomendación, nuevamente, de Montes i Bradley. En tal concepto merece Montes i Bradley la distinción de un "eficiente propulsor de este Museo". ${ }^{22}$

Al igual que posiblemente la de Pedone, la relación de Filloy con Montes i Bradley se remonta por fuera de los límites de la ciudad de Río Cuarto. Según Montes-Bradley E., Olmos y Montes-Bradley N. (2016) su vínculo se estableció en la época de estudiantes, dado que Montes i Bradley, si bien de otra ciudad, también era abogado. La amistad entre ambos hombres se adjudica, sin embargo, específicamente al amplio rango de intereses artísticos e intelectuales en común. Aparte de su trabajo como crítico en los diarios La Capital y La Nación, Montes i Bradley fue promotor de varios emprendimientos culturales, entre ellos la realización de biografías de artistas y de la revista Paraná.

Aun así, la dimensión altruista de estos aportes deben ser matizados teniendo en cuenta la red de intercambios de capital simbólico que operaron entre estos dos interlocutores. Si las colaboraciones y la ayuda de Montes i Bradley fueron asiduas hasta decidir autodenominarse "en ad honorem representante" del Museo (Montes-Bradley E. et. al. 2016, p. 34) también se establecieron de manera continua los pedidos a Filloy por parte del crítico para que colaborara en los suplementos artísticos que patrocinaba:

Al fin de cuentas, es esta la primera vez que voi [sic.] a circular en libro con temas plásticos, i [sic.] no todos tienen la obligación de conocerme a través del boletín -cuyo Balanza le irá pronto- $\mathrm{i}$ [sic.] de Paraná u otras colaboraciones en diarios, etc. El camino de Manuel Musto está destinado a venderse o al menos, circular por toda América, i [sic.], perdóneme la franqueza i [sic.] el pedido, quiero, me halagaría, el salvoconducto de sus palabras que conozco amigas, justas i [sic.] por sobre todo responsables.(Montes-Bradley E. et. al., 2016, p.57).

Filloy, por su parte, no solo obtenía como rédito incrementar la colección del museo sino, en simultáneo, atizaba la construcción de un renombre propio como especialista en el campo de las Bellas Artes. A su vez, propulsaba el interés de los artistas por donar sus 
obras a cambio de comentarios favorables del escritor en la prensa. Estos términos de intercambio pueden verse directamente explicitados por Montes i Bradley: "ya que me imagino que a la llegada de este modesto envío dos líneas dirás en los diarios locales para satisfacción de los autores, que tan bien se han comportado conmigo" (Montes-Bradley E. et. al. 2016, p. 33).

Por otro lado, no se debe descartar el interés por parte de Montes i Bradley de obtener un rédito económico para ciertos artistas pertenecientes a su red de influencia. En 1938 ingresa al museo un autorretrato de Berlengeri que "obtuvo el Premio Estímulo en el XIV Salón de Otoño adquirido por la Comisión Municipal de Bellas Artes de Rosario" (Libro de Actas... 1933-1943, n¹8); esta obra, se indica, fue adquirida "por la suma de 100 pesos nacionales", monto que Montes i Bradley se había encargado previamente que se otorgase:

ahora bien a este muchacho autor del óleo, cuya situación es precaria en extremo, a pesar de lo cual la comisión de aquí no fue capaz de adquirirle a un par de cientos de pesos, su obra premiada, se trataría de darle por "autorretrato" un billete de $100 \$$, con lo que el cuadro pasaría a ser adquisición (Montes-Bradley E. et. al. 2016, p. 33).

A esta red de intercambio de influencias presente en la gestación de otras colecciones de museos (Blasco 2011c; Carman 2013; Montini 2008) debe sumarse una particularidad propia del Museo Municipal de Bellas Artes de Río Cuarto: se trata de la vocación de escritor de su director y del entramado de su red de relaciones, tejidas no solo para conformar colecciones sino también para poner en circulación sus propias obras literarias. Así, junto con el envío de las obras plásticas, en la correspondencia en torno a la compra de 1937, se indica que Filloy había solicitado a Montes i Bradley la dirección postal de los autores que ingresaban a la colección:

en homenaje de amistad que tu bien aquilatas, paso a decirte cuanto me solicitas, primeramente direcciones maría Carmen araoz alfaro - mause 1760 (bs. as.) [sic.] juan berlengieri carballo -moreno 1168 depto $2^{\circ}$ (rosario) [sic.] (...) josefina siccard redl [sic.] (a cargo de la sra. margarita n. de neuschlosz) san Luis [sic.] 3443 (rosario) [sic.] Sergio sergi - museo rosa galisteo de rodríguez [sic.] - plaza $1^{\circ}$ de mayo- (santa fe) [sic.] (...) juan carlos castagnino - mexico 311 (bs.as) [sic.] (Montes-Bradley E. et. al. 2016, p. 35). Por su parte, Montes i Bradley le recomienda a Filloy que envíe sus escritos literarios solo a alguno de ellos: ahora, al propósito tuyo de remitirles tus obras, perdóname que confidencialmente te indique que puedes hacerlo a María Carmen y Sergio Sergi por cuanto son ellos los que habrán de saber leerlas. He visto en alguna biblioteca en bs. as. (i [sic.] te diré cuanto te vea, a quien pertenecía) estafen! [sic.] a medio leer, (más disculpable hubiera sido: sin leer), por lo que creo, debes remitir tus obras, a quienes las lean y las entiendan o procuren entenderlas (Montes-Bradley E. et. al. 2016, p. 36).

Se puede trazar como hipótesis que el tejido de relaciones con artistas que Filloy promovió para robustecer la colección del Museo Municipal de Bellas Artes operaba en simultáneo como modo de afianzar su lugar de escritor en un campo intelectual más basto que el de Río Cuarto. Más allá de la correspondencia citada con Montes i Bradley, una carta de Leónidas Gambartes datada el 29 de julio de 1939 (a ocho días del ingreso al museo de una donación suya) donde el artista plástico agradece el envío de Aquende ${ }^{23}$ orienta a pensar que el proceso de gestación del primer patrimonio artístico de la ciudad en la que eligió vivir tuvo para su director la capacidad de propiciarle, en correlación, estrategias para su consagración como literato. Facultad que, a su vez, se potenciaba en la 
medida que el acervo en ascenso del museo iba prestigiando la propia esfera cultural donde Filloy se movía.

En ese mismo sentido, pueden entenderse las donaciones efectuadas por organizaciones por él presididas o de las que formaba parte. Para mencionar un caso, pudimos documentar que el Club Sportivo y Biblioteca Atenas envió por lo menos cuatro obras; ${ }^{24}$ a su vez, la Biblioteca Mariano Moreno contribuye con un óleo de la pintora cordobesa Rosalía Soneira. ${ }^{25} \mathrm{~A}$ estas contribuciones, se deben adicionar las realizadas por el propio Filloy, que en los diez años analizados dona aproximadamente treinta y cinco piezas artísticas.

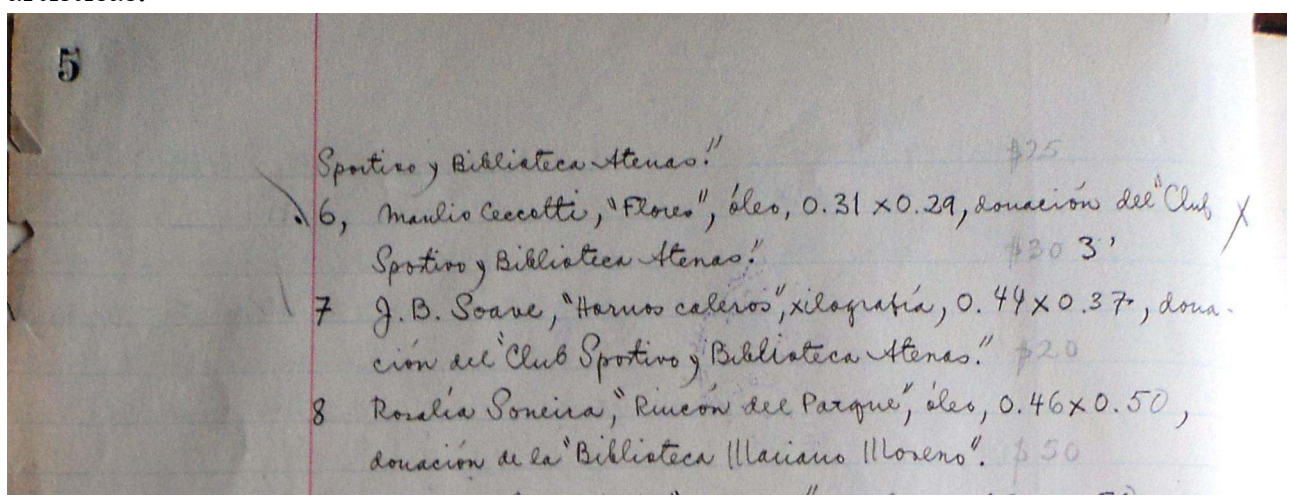

IMAGEN³: Donación de obras realizada por la Biblioteca Mariano Moreno y por el Club Sportivo y Biblioteca Atenas al Museo Municipal de Bellas Artes. Extracto del Acta $n^{\circ} 2$, fechada el 1 de agosto de 1933, del Libro de Actas del Museo Municipal de Bellas Artes de Río Cuarto, 1933-1943.

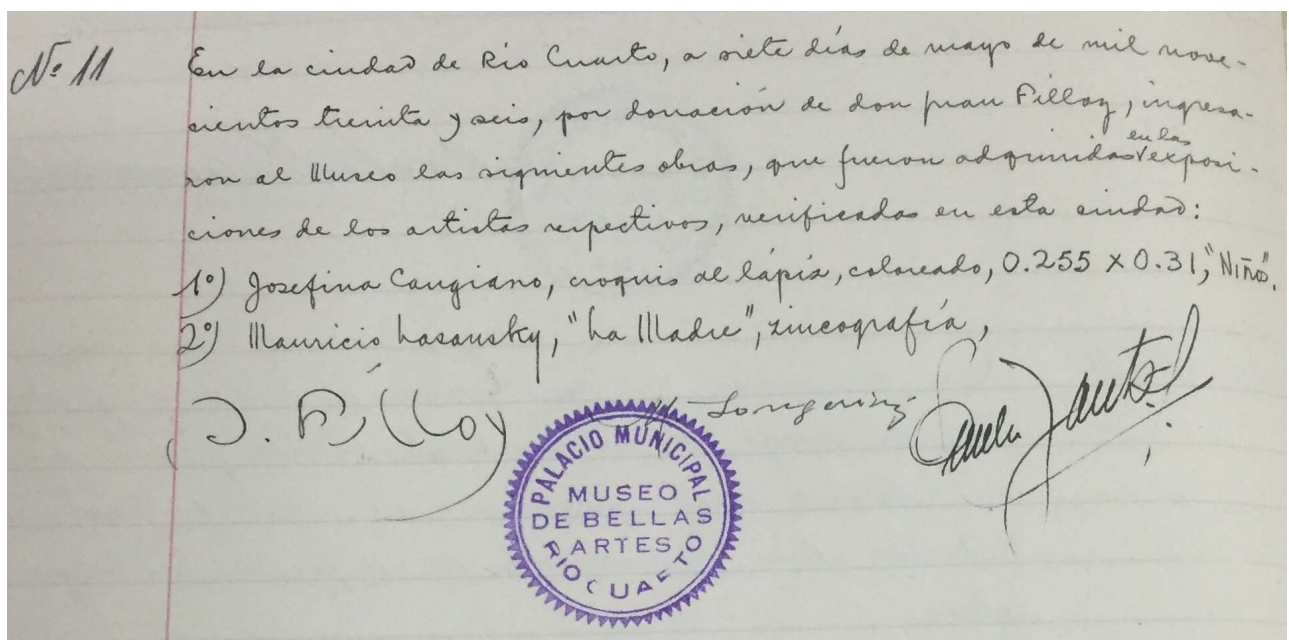

IMAGEN N4: Donación de obras realizada por Juan Filloy al Museo Municipal de Bellas Artes de Río Cuarto. Acta $n^{\circ} 11$, fechada el 7 de mayo de 1936, del Libro de Actas del Museo Municipal de Bellas Artes de Río Cuarto, 1933-1943.

La vinculación del Museo Municipal de Río Cuarto con entidades nacionales posiblemente mereciera otro apartado. No obstante, en continuidad con el lineamiento planteado hasta aquí, nos interesa remarcar la importancia que para Filloy tuvieron cada una de las presencias de instituciones nacionales a las que se encarga de hacer figurar en actas; en especial, la exhibición de las obras premiadas en el XXV Salón Nacional de Bellas Artes. Acaecido el 5 de diciembre de 1935, el evento tiene lugar en la Sala Magna del Palacio Municipal y en las dependencias anexas al Museo de Bellas Artes. "Prestigiado" con la presencia del Subsecretario de la Dirección Nacional, se recalca también que en el acto inaugural hizo uso de la palabra "el señor delegado de la Entidad Nacional: Don Alejandro Castagnino". Por otra parte, se destaca la acogida de la prensa local por "la adhesión 
prestada a este acontecimiento de verdadera significación artística", mientras que del resto de la ciudadanía de Río Cuarto no solo se indica que "desfiló los cinco días de la exposición" sino el hecho de que manifestó "comprensión y cordialidad (...) tanto a la obra de arte como a los artistas". De esta forma, se deja asentada la presencia de un público en Río Cuarto con la capacidad para entender y apreciar este tipo de eventos culturales". También queda por escrito la adecuación de las instalaciones para este tipo de muestras, tal como da cuenta "la complacencia de la delegación y artistas por las comodidades que ofrece el Palacio Municipal para desatacar la jerarquía de estas exposiciones". El acontecimiento no solo es aprovechado para generar la idea de un ambiente cultural acorde a las exigencias de las instituciones culturales centrales; además, a raíz del mismo se permite subrayar la importancia de otras instituciones creadas o bien integradas por Filloy para el sostenimiento de ese campo intelectual en ciernes: "finalmente, queda consignado el agradecimiento (...) a (...) la colaboración espontanea de la juventud de la Biblioteca Moreno, Club Atenas y periódico Impulso que no escatimó ningún esfuerzo en pos del éxito rotundo que obtuvo la exposición de las obras premiadas". ${ }^{26}$

El esfuerzo de Filloy para que el museo por él dirigido fuese una parte integrante de las principales instituciones artísticas del país queda también documentado en el Libro de Actas del museo. En este caso es el presidente Justo quien "accedió de tal manera a una petición del director" ${ }^{\prime 7}$ para que el 7 de abril de 1937 ingresaran al museo cuatro nuevas obras. Se debe destacar también la contribución del Museo Nacional de Bellas Artes efectuada un año antes (el 31 de mayo de 1936) de cinco óleos, entre ellos uno de Graciano Mendilaharzu; ${ }^{28}$ sus motivaciones, sin embargo, no podemos asegurar que correspondan a gestiones impulsadas por relaciones privadas de Filloy.

Si bien la colección del Museo Municipal se formó principalmente a raíz de los aportes de actores privados o de instituciones que respondieron a los vínculos interpersonales que Filloy trazó - de manera directa o mediada-con sus respectivos directores, existió también un moderado apoyo por parte del Estado. El 1 de agosto de 1933 se adquieren a través de un subsidio otorgado por el "Honorable Senado de la Provincia de Córdoba" y del "Honorable Consejo Deliberante" diez obras, entre ellas un óleo de José Malanca. Finalmente, si bien lo recapitulado no satura las líneas que permitirían abrir un análisis exhaustivo del acervo del Museo Municipal de Río Cuarto, los casos presentados tienen la contundencia suficiente como para advertir la vigencia que, aun en los años que iniciaron la participación activa del Estado en políticas patrimoniales, mantuvieron las prácticas privadas en la conformación de colecciones de museos estatales. Lejos de constituirse en una desventaja, la falta de una política estatal precisa, le permitió a Filloy moverse con la libertad y versatilidad suficiente como para articular "intereses y voluntades de diverso tipo y de diversas esferas sociales y públicas" (Eujanian 2013, p. 3) y consolidar un campo intelectual y artístico acorde a sus propios intereses.

Conclusión: La Trapalanda del Sur cordobés

Si el acta que formalmente dio por fundado el Museo Municipal de Bellas Artes de Río Cuarto dató de un 5 de julio, para realizar su acto inaugural se decidió esperar cuatro días más. El 9 de julio no solo se realizó el acto oficial y se abrieron las puertas de la institución al público, sino que se dio lugar al "Primer Salón de Invierno de Pintura y Escultura". Este evento, que contó con la presencia del delegado y miembro de la Comisión Provincial de Bellas Artes, estuvo dedicado exclusivamente a la producción artística de la provincia contando con la exposición de "cincuenta y siete artistas de Córdoba y Río Cuarto". 
Entender que, tal como fue estudiado por Bertoni (1992), desde fines del siglo XIX las conmemoraciones juegan un rol marcado en tanto operaciones performativas que exceden el ámbito de lo discursivo para extenderse a otros dispositivos experienciales y que permiten la legitimización de prácticas políticas por más que sean ideológicamente lejanas (Bisso y Kahan, 2014) impide adjudicar la fecha de la inauguración del Museo Municipal de Bellas Artes a una mera coincidencia.

En efecto, recuerda Ariel Magnus (2017) que el hecho de que el Museo hubiese sido inaugurado un 9 de julio fue una de las bases argumentativas del proyecto de ley que el diputado Carlos Duarte presentó para que le otorguen un subsidio a la reciente institución:

Allí, donde hace un siglo se levantaba inconmovible el fortín de la concepción del Río Cuarto, ofreciendo una lucha contra la barbarie, desde el 9 de julio de 1933, merced al esfuerzo privado, el Museo Municipal de Bellas Artes de Río Cuarto realiza su lucha en favor de la divulgación del arte (Magnus 2017, p. 125).

La singularidad del argumento debe matizarse en el marco de la cuantiosa cantidad de prácticas culturales que en los años 30 se sostienen a partir de su ligazón con acontecimientos relevantes de la historia argentina. Los usos del pasado, si bien no pueden considerarse una práctica iniciada en la denominada por José Luis Torres “década infame", ${ }^{29}$ tienen sin embargo en esos años un desarrollo considerable. Resume Cattaruzza (2001) la extensión de este fenómeno: “los historiadores, el Estado, los partidos políticos, los intelectuales que reflexionaban sobre las peculiaridades nacionales en ensayos que siempre incluían una perspectiva histórica, parecían entender en los años treinta que el pasado podía tener alguna eficacia sobre la situación presente" (2001, p. 433); si bien aclara que las imágenes de la historia de la Argentina desde donde se legitimaban acciones $\mathrm{u}$ objetivos del presente no estaban exentas de contradicciones, incluso en el interior de agrupaciones con un aparente lineamiento ideológico común (Cattaruzza 2001).

De hecho, más allá de la complejidad teórica de conceptos como el de 'nación’ y 'nacionalismo', cuyo estudio excede el propósito de este artículo, la elección de abordar una investigación sobre los años 30 vinculada a la problemática de la identidad nacional es conflictiva por sí misma. Sobre todo, como en este caso, si se desea tener en cuenta su significancia para el campo de la cultura. A la tematización casi salvaje de "lo nacional" que Terán (1986) adjudica como representativa de la producción literaria de la época, Gramuglio (2013) le contrarresta una interpretación del período que encuentra este tema como uno de los ejes de constancia respecto a las décadas precedentes y, de esta forma, no necesariamente característico. Entre estas dos posturas podríamos ubicar el amplio espectro de significaciones que la crítica ha trazado sobre el período cultural y su relación con la problemática de lo nacional (Romero 1965; Sarlo 1968; Garulli 1995; Devoto 2005; Tato 2009; Viñas 2007; Manzoni 2009; Saítta 2001; Finchelstein 2010; Spektorowski 2015). Con respecto a los procesos de construcción del patrimonio histórico en la década del 30, Blasco (2012a) advierte a partir de la serie de bibliografía citada (Béjar 1992, pp. 109-125; Bertoni 2001; Devoto 1999; Finchelstein 2002, pp. 95-112) un núcleo interpretativo que coincide en ver "los intereses del Estado por instalar una pedagogía patriótica mediante la proliferación de museos y lugares evocativos" (p. 3) como una característica de la época.

Inscripto en esta coyuntura, el proceso formativo del Museo Municipal de Bellas Artes de Río Cuarto se vio estrechamente vinculado por los modos en que su director buscó afianzar su capital social y simbólico para insertarse en un campo cultural más amplio 
que el que se comenzaba a gestar en la ciudad del sur de Córdoba. Pero, a su vez, el mismo locus (Martínez 2013) desde donde se desplegaron dichas prácticas proveyó a Filloy de un sustrato ideológico suficiente como para forjar un sistema institucional capaz de articularse con configuraciones identitarias de la nacionalidad ya afianzadas. En efecto, la asociación anteriormente citada entre la campaña roquista de 1880 y la fundación del Museo Municipal de Río Cuarto en 1933 no puede adjudicarse únicamente a una licencia poética del diputado Duarte alentada por la coyuntura socio-histórica. La praxis intelectual surcordobesa tuvo históricamente como horizonte identitario central "la dura batalla entre la Civilización y el Desierto y la gloriosa epopeya de la Cruz y de la Espada en esa otrora ignota tierra de la Cochancharava" (Escudero 2015, pp. 57-58) y el propio Filloy se encargó de reforzarlo tanto en una parte de su producción poética (cuya expresión más evidente será Urumpta) como en los discursos en torno a las instituciones culturales por él promovidas. Como ejemplo emblemático podemos citar los argumentos con los que la Asociación Amigos del Arte convoca a erigir, en 1948, un monumento a la Campaña del Desierto:

poniendo fe en el futuro arriesgaron su vida, sacrificaron sus intereses y no se amilanaron ante los estragos frecuentes de los malones, colocaron los mojones de la civilización y del progreso, haciendo posible que las sucesivas generaciones pudiesen disfrutar de los frutos de tantos esfuerzos, sacrificios y heroísmos por aquellos realizados (Escudero 2015, p.188). A su vez, en un reportaje brindado en 1938, Filloy vuelve a ubicar en un mismo plano la creación del Museo Municipal, y su papel en ella, con la campaña dirigida por Roca: "recién salimos de isletas de cultura, como los pioneers de hace ochenta años, a colonizar el desierto del espíritu" (Magnus 2017, p.126).

Pero si bien Filloy recupera los motivos de la gesta civilizatoria del 80 - en tanto construcción épica de conquista civilizatoria frente a un campo yermo de cultura- la imagen identitaria que configura para la ciudad de Río Cuarto se sostiene también en las propias fracturas que el modelo decimonónico experimenta, desde finales del siglo XIX, por la reacción ante la afluencia inmigratoria y que se refuerzan, en la década del 30, a partir del impacto de la crisis económica y la puesta en discusión a nivel global del sistema liberal. En otras palabras, se inserta en la trama que es posible trazar entre la desvinculación del proyecto civilizatorio respecto de la idea de progreso y las derivaciones que en los 30 toman cauce en los replanteos económicos de los nacionalistas. 30

Específicamente, la pugna entre civilización y progreso se construye como uno de los motores de la épica filloyana a partir de la cual propone una nueva fundación identitaria para Río Cuarto; pero que, esta vez, inscriba a la ciudad como vector de un avance cultural y no solo del progreso económico. ${ }^{31}$ Así en "Balance Enfático de Río Cuarto" reclama que la esfera utilitaria que marcó de manera unilateral el proyecto civilizatorio de su ciudad sea recreado en términos culturales: "los logros alcanzados conciernen exclusivamente a la esfera utilitaria. La historia intelectual, artística y científica está por hacerse todavía. Ostentamos récords agropecuarios, pero no páginas épicas, performances deportivas, pero no cantos que entusiasmen" (Filloy 2014, p. 188).

No obstante, a diferencia de las rupturas o reelaboraciones ${ }^{32}$ con el modelo liberal acaecidas para la época, que pugnaban por la construcción de un nuevo sentido identitario hegemónico pero dentro de una posición privilegiada o central en el campo intelectual, la gestación del patrimonio cultural dentro de ámbitos periféricos como es el de una ciudad no capital de provincia debe ser interpretado desde su condición de subalternidad. La refundación identitaria de Río Cuarto proyectada por Filloy es 
indisoluble de la construcción de un nuevo modelo de la nación argentina que le permita a esa ciudad cordobesa desplazarse hacia un lugar central. En este sentido, la conformación del Museo Municipal de Bellas Artes se vincula fuertemente con otros proyectos culturales de provincias argentinas dedicadas primariamente a actividades mercantiles. Entre ellos, la conformación del Museo Castagnino en la ciudad de Rosario, incluida en el proceso de modernización "a la europea" de la ciudad en los años 20 y a partir de la cual "se quería combatir la repetida caracterización de Rosario como una urbe fenicia” (Montini 2008, p. 63). ${ }^{33}$

Junto a la reconversión en términos culturales de la empresa militar que, simbólicamente, dio lugar al Estado Moderno Argentino, Filloy retoma otro de los mitos originarios de la Argentina como es el de la ciudad de Trapalanda: "Tres siglos fueron necesarios para virtualizar el mito" (Filloy 2014, p. 171), Trapalanda sigue acunando todavía el interés de los historiadores. En el sur de Córdoba, en un sur metafísico de profusos territorios, debe alzarse aún el esplendor áureo de la ciudad abscóndita. El entusiasmo revive a menudo la llama caduca y la antigua prestancia ¡¡Vamos!, ordena. Muchos van. Pero retornan con la misma respuesta: Nada, nada... Es que no ven. ¡Trapalanda está haciéndose! (Filloy, 2014, p.164).

Reelaborando así una tradición historiográfica local que eligió ver en esa región de la provincia de Córdoba a la "ciudad de oro" añorada por los conquistadores españoles (Escudero 2015, p. 59), inviste al mito de un manto de realidad definiendo la riqueza de Río Cuarto a partir del capital cultural por él gestado. Más allá de la cualidad civilizatoria que, como marcamos, encuentra Filloy en la gesta del patrimonio cultural y a partir de la cual crea un nueva imagen identitaria para la ciudad de Río Cuarto -y en correlación una posición central de su figura en el nuevo panteón municipal-, lo interesante del caso es la conciencia de la incidencia política, en términos de producción y trasmisión social de significados (Castilla 2010), de ciertos usos del pasado. Vincular la fundación del Museo de Bellas Artes de Río Cuarto al mito de Trapalanda ${ }^{34}$ y a la "campaña del desierto" ubica la conformación del patrimonio municipal en el plano nacional y recoloca a la ciudad periférica de Río Cuarto como centro civilizatorio del país. En otros términos, inventa una tradición (Hobsbawn 2002) para esa región del interior del país a partir de la elección deliberada de una continuidad ficticia con hechos (o mitos, en este caso) del pasado, acontecimientos que, a su vez, fueron consolidantes de una identidad nacional que se busca resignificar. De este modo, la tradición inventada legitima la conformación del Museo Municipal de Bellas Artes de Río Cuarto a la vez que cimienta su incorporación dentro del patrimonio cultural de la nación. En este proceso, Filloy, por su parte, se sitúa en condiciones de disputar un lugar hegemónico en el campo intelectual nacional. Finalmente, lo expuesto nos invita a reflexionar sobre la compleja red de relaciones que la polaridad centro y periferia oblitera. Lejos de constituirse en receptores pasivos de imágenes identitarias consolidadas a la luz de los intereses de la metrópolis, las provincias (en este caso una ciudad en el interior del interior) "fueron proveedoras de imágenes, representaciones y símbolos utilizados en diversos momentos como hebras para hilvanar relatos identitarios con pretensión nacional" (Eujanian 2013, p. 2). Fuentes Conversando con Antonio Pedone. Director del Museo Provincial de Bellas Artes. (29 de noviembre de 1930). La Voz del Interior. Disponible en http: //www.museocaraffa.org.ar/ blogcentenario/?p=901. Libro de Actas del Museo Municipal de Bellas Artes. (1933-1943). Archivo Museo Municipal de Bellas Artes. 
Carta de Antonio Pedone a Arturo U. Illia, fechada "Córdoba, 10 de noviembre de 1942". Disponible en http://www.museocaraffa.org.ar/blogcentenario/?p=781

Carta de Leónidas Gambartes a Juan Filloy, fechada “Rosario- 28 de julio de 1939”. Archivo Histórico Municipal de Río Cuarto.

Agüero, A. C. (2009). El espacio del arte. Una microhistoria del Museo Politécnico de Córdoba entre 1911 y 1916. Córdoba: Editorial de la Facultad de Filosofía y Humanidades.

Agüero, A. C. y García, D. (Eds.). (2016). Culturas interiores: Córdoba en la geografía nacional e internacional de la cultura. Villa María: Eduvim.

Ambort, M. (1992). Juan Filloy, el escritor escondido. Buenos Aires: Aguilar

Baldasarre, M. (2006). Los dueños del arte. Coleccionismo y consumo cultural en Buenos Aires. Buenos Aires: Edhasa.

Baldasarre, M. I. (2013). Museo universalista y nacional. El lugar del arte argentino en las primeras décadas de vida institucional del Museo Nacional de Bellas Artes de Buenos Aires. A Contracorriente, 10 (3), 255-278.

Bergel, M. (2012). Flecha, o las animosas obsesiones de Deodoro Roca. En D. Roca, Obra Reunida. Tomo IV. Córdoba: Editorial de la Universidad de Córdoba.

Bertoni, L.A. (1992). Construir la nacionalidad: héroes, estatuas y fiestas patrias, 1887-1891. Boletín del Instituto de Historia Argentina y Americana “Dr. E. Ravignani”, 3ra serie (5), 77-111.

Bertoni, L. A. (2001). Patriotas, cosmopolitas y nacionalistas. La construcción de la nacionalidad argentina a fines del siglo XIX. Buenos Aires: Fondo de Cultura Económica.

Bisso, A., Kahan, E y Sessa, L. (Eds.). (2014). Formas políticas de celebrar y conmemorar el pasado (1930-1943). Buenos Aires: Ceraunia.

Blasco, M. E. (2011a). Comerciantes, coleccionistas e historiadores en el proceso de gestación y funcionamiento del Museo Histórico Nacional. Entrepasados, (36-37), 93-111. Blasco, M. E. (2011b). La hora del museo: la 'Sala Uriburu' del Museo Histórico y Colonial de la Provincia de Buenos Aires (Luján, 1932). Anais do Museu Paulista: História e Cultura Material, 19, (1), 113-132.

Blasco, M. E. (2011c). Un museo para la colonia. El Museo Histórico y Colonial de Luján (1918-1930). Rosario: Prohistoria.

Blasco, M. E. (2012a). La formación del Parque Evocativo y Museo 'Los Libres del Sur' (Dolores, 1939- 1942). Cuadernos del Sur/Historia, (39), 9-36.

Blasco, M. E. (2012b). De objetos a “patrimonio moral de la nación”. Prácticas asociadas al funcionamiento de los museos históricos en la Argentina de las décadas de 1920 y 1930. Nuevo Mundo Mundos Nuevos. Nouveaux mondes mondes nouveaux-Novo Mundo Mundos NovosNew world New worlds. doi: 10.4000/nuevomundo.64679.

Carman, C. (2013). Los orígenes del Museo Histórico Nacional. Buenos Aires: Prometeo. Castilla, A. (Comp.). (2010). El museo en escena. Política y cultura en América Latina. Buenos Aires: Paidós/Fundación Typa.

Cattaruzza, M. (2001). Crisis económica, Avance del Estado e Incertidumbre Política (1930-1943). Buenos Aires: Sudamericana.

Constantín, M. T. (1999). El hombre propone... y la época dispone. O cómo se dibujó el perfil del Museo Rosa Galisteo de Rodríguez. Porto Arte, 10(18), 83-94.

De Olmos, C. (2006). Filloy en tres tiempos. Correspondencia en torno a Balumba. Córdoba: Alción Editora - Centro de Estudios Avanzados.

Devoto, F. (2005). Nacionalismo, fascismo y tradicionalismo en la Argentina moderna. Una historia. Buenos Aires: Siglo XXI. 
Escudero, E. (2015). Cultura histórica y usos del pasado. Memoria, identidades y política en una experiencia local (Río Cuarto, 1947-1986). Tesis de doctorado. Universidad Nacional de Córdoba.

Eujanian, A. (2013). El pasado de las provincias. Actores, prácticas e instituciones en la construcción de identidades y representaciones de los pasados provinciales en la Argentina entre la segunda mitad del XIX y la entreguerra. Dossier $N^{\circ} 33$ de Historiapolítica.com. Disponible en http://historiapolitica.com/dossiers/pasadosprovinciales.

Farro, M. (2008). Historia de las colecciones en el Museo de La Plata, 1884-1906: naturalistas viajeros, coleccionistas y comerciantes de objetos de historia natural a fines del siglo XIX. Tesis de Doctorado. Facultad de Ciencias Naturales y Museo. Universidad Nacional de La Plata.

Filloy, J. (1937). Caterva. Buenos Aires: Ferrari hermanos.

Filloy, J. (2014). Urumpta. Córdoba: Unirio

Finchelstein, F. (2002). Fascismo, liturgia e imaginario. El mito del general Uriburu y la

Argentina nacionalista. Buenos Aires: Fondo de Cultura Económica.

Finchelstein, F. (2010). Fascismo trasatlántico. Ideología, violencia y sacralidad en Argentina y en Italia, 1919-1945. Buenos Aires: Fondo de Cultura Económica.

Garulli, L. (1995). El treinta. Una década en transición. Buenos Aires: Universidad de Buenos

Aires.

González Tuñón, E. (1932). El tirano. Novela sudamericana de honestas costumbres y justas liberalidades. Buenos Aires: M. Gleizer-Editor.

Gramuglio, M. T. (2013). Nacionalismo y Cosmopolitismo en la literatura argentina. Rosario: Editorial Municipal de Rosario.

Heinich, N. (2014). La fábrica del patrimonio. Apertura y extensión del corpus patrimonial: del gran monumento al objeto cotidiano, (D. C. Ruiz y A. Ávila Gómez, trad.). Apuntes: Revista de estudios sobre patrimonio cultural-Journal of Cultural Heritage Studies, 27 (2), 8-25.

Hobsbawm, E. (2002.) Introducción: la invención de la tradición. En E. Hobsbawm y T. Ranger (Eds.), La invención de la tradición (pp. 7-21). Barcelona: Crítica.

Kohan, N. (1999). Deodoro Roca, el hereje. Buenos Aires: Ed. Biblos.

Magnus, A. (2017). Un atleta de las letras. Juan Filloy. Córdoba: Eduvim.

Malosetti Costa, L. (2001). Los primeros modernos: arte y sociedad en Buenos Aires a fines del siglo XIX. Buenos Aires: Fondo de Cultura Económica.

Malosetti Costa, L. (2010). Arte e historia. La formación de las colecciones públicas en Buenos Aires. En A. Castilla (Comp.), El museo en escena. Política y cultura en América Latina (pp. 71-88). Buenos Aires: Paidós/Fundación Typa.

Malosetti Costa, L. (2016). Aesthetic Artefacts or Documents? Museums of Art and History in Late Nineteenth-Century Buenos Aires. Museum History Journal, 9 (1), 108-120.

Manzoni, C. (2009). Rupturas. Historia crítica de la literatura argentina, Buenos Aires: Emecé. Martínez, A. T. (2013). Intelectuales de provincia: entre lo local y lo periférico. Prismas (17), 169-180.

Montes-Bradley, E., De Olmos, C., y Montes-Bradley, N. (2016). El amigo de Filloy. Cartas de R. E Montes i Bradley a Juan Filloy (1935-1976). Disponible en https://issuu.com/ eduardomontes-bradley/docs/el_amigo_de_filloy Montini, P. (2008). Del caduceo a las musas: un inventario del coleccionismo profesional en Rosario. La colección artística de Juan B. Castagnino, 1907-1925. En P. Artundo y C. Frid (Eds.), Coleccionismo de arte en Rosario: colecciones, mercado y exposiciones, 1900-1970 (pp. 21-66). Buenos Aires: Fundación Espigas/ Cehipe. 
Podgorny, I. (2005). La mirada que pasa: museos, educación pública y visualización de la evidencia científica. História, Ciências, Saúde-Manguinhos, 12, 231-264.

Podgorny, I. y Lopes, M. M. (2013). Trayectorias y desafíos de la historiografía de los museos de historia natural en América del Sur. Anais do Museu Paulista: História e Cultura Material, 21(1), 15-25.

Portantiero, J. C. (1978). Estudiantes y política en América Latina. 1918-1938. El proceso de la Reforma Universitaria. México: Siglo XXI.

Requena, P. M. (2009). La Reforma Universitaria en dos tiempos. Deodoro Roca, la noción de generación y los imaginarios reformistas (1918-1936). Cuadernos de Historia. Serie Economía y Sociedad, (11), 109-130.

Revel, J. (2014). La fábrica del patrimonio. Tarea. Anuario del Instituto de Investigaciones sobre el Patrimonio Cultural, Universidad Nacional de San Martín, (1), 15-25.

Romero, J. L. (1965). El desarrollo de las ideas en la sociedad Argentina del siglo XX. México: Fondo de Cultura Económica.

Saítta, S. (2001). Entre la cultura y la política. En M. Cattaruzza, Crisis económica, Avance del Estado e Incertidumbre Política (1930-1943) (pp. 383-428). Buenos Aires: Sudamericana.

Sanguinetti, H. (2003). Trayectoria de una flecha. Las obras y los días de Deodoro Roca. Buenos Aires: Librería Histórica.

Sarlo, B. (1968). Una modernidad periférica: Buenos Aires 1920 y 1930. Buenos Aires: Nueva Visión.

Spektorowski, A. (2015). Argentina 1930-1940: nacionalismo integral, justicia social y clase obrera. Estudios Interdisciplinarios de América Latina y el Caribe, 2, (1).

Suárez, C. A. y Saab, J. (2012). El Estado, Ricardo Levene y los lugares de memoria. Clío y Asociados, (16), 211-227.

Tato, M. I. (2009). Nacionalistas y conservadores, entre Yrigoyen y la 'década infame'. En L. Bertoni y L. De Privitellio (Comps.), Conflictos en democracia: la vida política argentina entre dos siglos, 1852-1943 (pp. 149-170). Buenos Aires: Siglo XXI.

Tentoni, V. (2016). Juan Filloy, el desaforado. Tesis de Licenciatura. Facultad de Periodismo y Comunicación Social, Universidad Nacional de La Plata.

Terán, O. (1986). En busca de la ideología argentina, Buenos Aires: Catálogos.

Vásquez, K. (2000). Intelectuales y política: la ‘nueva generación’ en los primeros años de la Reforma Universitaria. Prismas. Revista de historia intelectual, IV, 59-75.

Viñas, D. (2007). La década infame y los escritores suicidas. Buenos Aires: Paradiso.

\section{NOTES}

1. Esta investigación pudo efectuarse gracias al aporte, colaboración e interés del actual director del Museo Municipal de Bellas Artes de Río Cuarto, Jorge Busnelli, que permitió el acceso al Libro de Actas de la institución y a la biblioteca donada por Juan Filloy.

2. Se agradece al director del Archivo Histórico Municipal de Río Cuarto, Omar Isaguirre, la facilitación del material así como la rigurosa información provista sobre la vida de Juan Filloy.

3. La aclaración que realiza Baldasarre (2006) respecto de los objetivos institucionales de algunos salones y exposiciones individuales finiseculares permite entender tanto las causas de la 
denominación de ‘Salón' para la primera colección de arte de la capital cordobesa como así los reparos de su director por continuar bajo esa signatura: "No quiero concluir a partir de esto que los móviles económicos y los de estímulo de la institucionalización artística fuesen excluyentes. Por el contrario, en las exposiciones celebradas por el Ateneo también las obras se ofrecían a la venta y el rédito económico era sin duda importante para los expositores. Sin embargo, en este proyecto artístico estaba muy presente el ideal 'civilizatorio' que consideraba al desarrollo de las bellas artes como un hito necesario para la inclusión de la Argentina entre las naciones avanzadas" (Baldasarre 2006, pp. 40,41). Se debe aclarar también que la idea de salón ancla su tradición en las exposiciones semipúblicas iniciadas en el Salon Carré (Salón Cuadrado) del Louvre.

4. Carta de Atonio Pedone a Arturo U. Illia, fechada "Córdoba, 10 de noviembre de 1942". Disponible en http://www.museocaraffa.org.ar/blogcentenario/?p=781

5. Debe notarse que en la fuente se refiere al Salón de Bellas Artes de Córdoba como museo.

6. En efecto, en el decreto que oficializa la creación del Museo Nacional de Bellas Artes se especifica como una de sus motivaciones "dotar a nuestro arte naciente de la institución oficial a que tiene derecho, para salvar del olvido y guardar en el tiempo las manifestaciones artísticas más interesantes de la inteligencia argentina" (Baldasarre 2013, p. 3). Para un análisis crítico de los primeros años del Museo Nacional de Bellas Artes, ver Baldasarre (2013) y Malosetti Costa (2010; 2016).

7. También Blasco (2011a) discute la idea de que el surgimiento y la organización de museos haya sido principalmente ideada desde las altas esferas oficiales. Hacia 1883, afirma, "las colecciones y museos privados ocupaban un lugar tanto o más importante que las promovidas por la estructura estatal" (Blasco 2011a, p. 12).

8. Entre los mecanismos que Blasco (2011b) reconstruye para la conformación de la sala Uriburu del Museo Histórico y Colonial siguen estando presentes la obtención de objetos con dinero privado de Udaondo, donaciones conseguidas a partir de sus relaciones personales y otras prácticas que, algunos años antes, tendieron a avalar "la decisión gubernamental de que un museo público se solventara en su mayor parte con aportes privados” (Blasco 2012b, p. 4). Por su parte, Eujanian (2013), lejos de ver como una limitación a la institucionalización tardía que en las provincias alcanzaron los espacios dedicados al estudio o conmemoración del pasado y a la prevalencia de una distinción difusa entre lo público y lo privado, entiende que estos factores promovieron el desarrollo por parte de particulares (sin una necesaria formación académica) de diversas iniciativas en el campo cultural, entre las que se encontró la organización de museos.

9. Se producirá para Blasco un cambio más categórico en la década de 1940 que "se caracterizará por el predominio de la historia y la frontera nacional avalada y regulada no ya por los 'intereses patrióticos' de los individuos sino por el andamiaje jurídico, administrativo y cultural ya diseñados entre la corporación de historiadores y los representantes del Estado" (Blasco 2012b, p. 9).

10. Si bien Juan Filloy (1894-2000) escribió más de 50 títulos, el carácter altamente prolífico del escritor no tuvo su correspondencia en el ámbito de los estudios especializados. Su obra, casi siempre relegada de las historias literarias, se difundió principalmente a través de ediciones de autor. Este hecho valió conjeturas diversas por parte de la crítica: desde su necesidad de mantener oculta su provocativa prosa dado la profesión de jurista que ejercía (Ambort 1992) hasta la idea de que esa forma de difusión ayudaba a sustentar una construcción mítica deseada de escritor (De Olmos 2006). Si bien no es el propósito de este artículo efectuar un análisis literario de sus escritos ficcionales, se realizarán algunas menciones de su producción que resulten afines a la temática abordada.

11. Libro de Actas del Museo Municipal de Bellas Artes de Río Cuarto, 1933-1943, nº 1.

12. Libro de Actas..., 1933-1943, nº 1.

13. Libro de Actas..., 1933-1943, nº 1. 
14. Libro de Actas..., 1933-1943, $\mathrm{n}^{\circ} 1$.

15. Libro de Actas..., 1933-1943, $\mathrm{n}^{\circ} 4$.

16. Libro de Actas..., 1933-1943, $\mathrm{n}^{\circ} 6$.

17. En relación, Irina Podgorny (2005) entiende que los museos de ciencias naturales constituyen en particular espacios donde los objetos están ligados a conflictos e intercambios propios de la desnaturalización que se produce entre el 'campo' desde el que son extraídos y su conversión en preparados para el microscopio, reacciones químicas y series de mediciones. En este sentido afirma que los museos y la colección "esconden otro mundo invisible: la historia de la misma sociedad constructora de ese museo, los conflictos enraizados a su origen y a su funcionamiento como lugares de trabajo y de investigación" (Podgorny 2005, p. 234). En trabajos posteriores recalca la necesidad de que la historiografía desarrolle estudios sobre las trayectorias de los objetos que reflexionen sobre cómo, procediendo de diversas tradiciones de uso, estos objetos convivieron y aún conviven en un espacio que, supuestamente, los incorporaba a un orden diferente (Podgorny y Lopes 2013). Por su parte, Malosetti Costa (2016) entiende que el estudio de la distribución, las funciones, la preservación y las historias que les dan significado a los artefactos visuales que conformaron el Museo Histórico Nacional y el Museo Nacional de Bellas Artes permiten una reflexión más acabada sobre las tensiones entre arte e historia en Argentina.

18. Petorutti, a quien Filloy debía conocer por haber participado ambos en la revista Fábula, dona, el 7 de enero de 1936, ya siendo director del Museo de Bellas Artes de La Plata, un dibujo de su autoría y una escultura del artista uruguayo L. Peña. (Libro de Actas... 1933-1943, n 9)

19. Libro de Actas..., 1933-1943, n 35.

20. Libro de Actas..., 1933-1943, n 43.

21. Filloy prologará la biografía de Manuel Musto editada por Montes i Bradley en 1942.

22. Libro de Actas..., 1933-1943, nº 16.

23. El envío del material literario es inferido por el propio artista plástico como modo de agradecimiento: "pienso que la razón de su envío lo motiva una modestísima acuarela mía". (Carta de Leónidas Gambartes a Juan Filloy, fechada "Rosario-28 de julio de 1939", Archivo Histórico de Río Cuarto.)

24. Libro de Actas..., 1933-1943, $\mathrm{n}^{\circ} 2$.

25. Libro de Actas..., 1933-1943, nº 2.

26. Libro de Actas..., 1933-1943, nº 8.

27. Libro de Actas..., 1933-1943, $\mathrm{n}^{\circ} 18$.

28. Libro de Actas..., 1933-1943, n 10.

29. Respecto de los modos de construcción de la nacionalidad que, desde fines del siglo XIX, operan a partir de conmemoraciones basadas en la apelación a un pasado patrio, ver Bertoni (1992).

30. La lógica antiimperialista -en cuyo anverso se ubicaba al liberalismo- fue uno de los aglutinantes decisivos de la etapa final de los nacionalismos de los $30 \mathrm{y}$ el concepto que permite trazar la principal conexión con la idea de nación proclamada por movimientos nacionalistas de izquierda y de derecha. De hecho, tres años después de la publicación de La Argentina y el Imperialismo Británico, Julio Irazusta apoya la candidatura de Alvear y se afilia a la UCR, a la que comienza a aceptar como único medio de lograr un gobierno antiimperialista y antiliberal. Un acercamiento similar realiza Gálvez, que, en su Vida de Hipolito Yrigoyen, relaciona el fascismo, en el que encuentra raíces socialistas, con el yrigoyensimo, en el que lee un espíritu corporativo. A su vez, el aprecio de la figura de Rosas se irá abriendo paso entre estos sectores, fortaleciéndose a partir de la Segunda Guerra Mundial.

31. En Caterva (1937), por ejemplo, se describe el desgaste del sistema agroexportador en sobreexplotación de una provincia donde se cultiva hasta en los cementerios; la capital de Córdoba, a su vez, se representa en estado de descomposición (dos de los personajes principales encuentran la muerte en esa ciudad; a la vez que sitios emblemáticos son invadidos por insectos) 
y degradada por un exceso de doctoralismo y clericalismo. El socavamiento que Filloy realiza de dos de los pilares civilizatorios de su provincia deben ser entendidos en el marco de un reposicionamiento de Río Cuarto como uno de los centros intelectuales de una nueva nación imaginada.

32. Señala Cattaruzza (2001) que, a diferencia de lo que primeramente puede pensarse, las reelaboraciones del pasado nacional que confirieron nuevas identidades a los proyectos políticos e intelectuales de los 30 no necesariamente se plantean en términos concordantes con la historiografía revisionista en auge. Para otorgar un ejemplo en el campo literario, podemos pensar la asociación que en la sátira política de González Tunón (1932) se realiza entre el tirano y la figura de Rosas.

33. Razones semejantes se aducen por Martín Rodríguez Galisteo en la gestación del Museo Rosa Galisteo de Santa Fe: "Nuestra provincia ha realizado progresos admirables en lo concerniente a la ganadería y agricultura, principales fuentes de la riqueza nacional, pero está retardada en lo que a la cultura artística y literaria se refiere" (Constantín 1999, p. 88). Es interesante remarcar que, trasladado a una escala internacional, uno de los promotores del Museo Nacional de Bellas Artes, Juan Benito Sosa, se vio en la necesidad de "contrarrestar los argumentos que sostenían que la Argentina era una nación eminentemente comercial y que todavía era prematuro pensar en su 'enaltecimiento intelectual y moral"' (Baldasarre 2006, p. 130).

34. La recuperación del mito de Trapalanda como marco de la conformación del Museo Municipal nos permite también trazar una relación diacrónica con las motivaciones de las primeras colecciones en tiempos coloniales que "reflejaban un interés por clasificar las riquezas naturales exportables al Viejo Mundo como promesa de mayores riquezas” (Castilla 2010, p. 21).

\section{ABSTRACTS}

The main objective of the article is to carry out a critical analysis of the formation processes and initial development of the Municipal Museum of Fine Arts of Río Cuarto (Córdoba) between 1933-1943. Emerged in the context of a growing interest of the State in the formation of national heritage, the Municipal Museum of Fine Arts of Rio Cuarto will be shaped, fundamentally, by the efforts promoted by its director: the writer from Cordoba, Juan Filloy. In this way, it will be a central focus of the article to explore the network of relationships and interests that made possible the gestation of the Museum as well as the specific dynamics of the peripheral cultural fields. In this framework, the Municipal Museum of Fine Arts of Río Cuarto will be inscribed in a wider plot of production, circulation and appropriation of stories and representations of the past. The research is mainly based on an examination of primary sources: the Minutes Book of the Municipal Museum of Fine Arts of Río Cuarto, which is still in its current location, and a series of letters addressed to Filloy, which we were able to examine in the Historical Municipal Archive of Río Cuarto. In addition, the correspondence of Ricardo Montes i Bradley to Filloy compiled in El Amigo de Filloy (2014) will play a relevant role in this work. Finally we analize some statements or speeches by Filloy himself taken from the biography of Juan Filloy recently written by Ariel Magnus (2017).

El artículo tiene como objetivo primordial realizar un análisis crítico de los procesos de formación e inicial desarrollo del Museo Municipal de Bellas Artes de Río Cuarto (Córdoba) entre 1933-1943. Surgido en el contexto de un creciente interés del Estado en la formación del 
patrimonio nacional, el Museo Municipal de Bellas Artes de Río Cuarto se conformará por el contrario y fundamentalmente por los esfuerzos promovidos por su director: el escritor cordobés, Juan Filloy. De esta manera, constituye un foco central del artículo explorar la red de relaciones e intereses que hicieron posible la gestación del Museo así como la dinámica específica de los campos culturales periféricos. En este marco, se inscribe al Museo Municipal de Bellas Artes de Río Cuarto en una trama más amplia de producción, circulación y apropiación de relatos y representaciones del pasado. La investigación se sustenta principalmente en el examen de fuentes primarias: el libro de Actas del Museo Municipal de Bellas Artes de Río Cuarto, que aún se conserva en su sede actual, y una serie de cartas dirigidas a Filloy, que pudimos examinar en el Archivo Histórico Municipal de Río Cuarto. Además cumple un rol relevante en este trabajo la correspondencia de Ricardo Montes i Bradley a Filloy recopilada en El Amigo de Filloy (2014). Finalmente contamos con algunas declaraciones o discursos del propio Filloy extraídas de la biografía sobre el escritor cordobés recientemente escrita por Ariel Magnus (2017).

\section{INDEX}

Keywords: Municipal Museum of Fine Arts of Río Cuarto, Juan Filloy, center-periphery, national identity

Palabras claves: Museo Municipal de Bellas Artes de Río Cuarto, Juan Filloy, centro-periferia, identidad nacional.

\section{AUTHOR}

\section{MARTINA GUEVARA}

Instituto de Investigaciones Gino Germani, Consejo Nacional de Investigaciones Científicas y Técnicas, Argentina.

Correo electrónico: guevaramartina@gmail.com 